\title{
Estudo do modelo SIR com imunidade cruzada
}

\author{
Dérek B. Prates* Caio Luiz T. F. Jardim Letícia A. F. Ferreira \\ Instituto de Ciência, Engenharia e Tecnologia, ICET, UFVJM, \\ 39301-000, Teófilo Otoni, MG \\ E-mail: derekbomfim@hotmail.com, caiodt4@hotmail.com, lettyali@hotmail.com, \\ Jaqueline M. da Silva \\ Universidade Federal dos Vales do Jequitinhonha e Mucuri- Instituto de Ciência, Engenharia e Tecnologia, ICET, UFVJM, \\ 39301-000, Campus Mucuri, Teófilo Otoni, MG \\ E-mail: jaqueline.silva@ufvjm.edu.br.
}

\section{RESUMO}

A modelagem matemática é uma ferramenta fundamental para análise, interpretação e descrição de fenômenos que acontecem na natureza. O estudo das epidemias, por exemplo, é feito através de modelos compartimentais, muitas vezes baseados em equações diferenciais, onde há uma análise dos aspectos epidemiológicos que facilitam a compreensão da dinâmica de epidemias em populações. Doenças como a Peste Bubônica, Gripe Espanhola e Malária, com altas taxas de mortalidade e morbilidade, dizimaram populações, limitando o crescimento demográfico e tornando-se um enorme problema de saúde pública.

O modelo SIR é uma das várias ferramentas matemáticas para a análise quantitativa e qualitativa das epidemias. Ele foi proposto por Kermack e McKendrick, em 1927, e sugere a divisão de uma população em três classes: suscetíveis, infectados e recuperados. Tal modelo é baseado em um sistema de equações diferenciais que representam a variação temporal destas classes.

Neste trabalho tal modelo será utilizado em uma população variante no tempo onde há co-circulação de duas epidemias com variantes hipotéticos. Será abordada também a chamada imunidade cruzada, que é a possibilidade de um organismo, já infectado com uma das variantes, adquirir certa resistência a outra. Admitindo, por simplicidade, que não há contaminação simultânea das duas variantes por um indivíduo, as equações que descrevem o modelo SIR (Castillo-Chavez,1989) nesta situação são:

$$
\left\{\begin{aligned}
\frac{d X}{d t} & =-\left[\beta_{1}\left(Y_{1}+V_{1}\right)+\beta_{2}\left(Y_{2}+V_{2}\right)\right] X+\mu-\mu X \\
\frac{d Y_{i}}{d t} & =\beta_{i}\left(Y_{i}+V_{i}\right) X-\left(\gamma_{i}+\mu\right) Y_{i} \\
\frac{d Z_{i}}{d t} & =\gamma_{i} Y_{i}-\left(\sigma_{j} \beta_{j}\left(Y_{j}+V_{j}\right)+\mu\right) Z_{i} \\
\frac{d V_{i}}{d t} & =\sigma_{i} \beta_{i}\left(Y_{i}+V_{i}\right) Z_{j}-\left(\gamma_{i}+\mu\right) V_{i} \\
\frac{d W}{d t} & =\gamma_{1} V_{l}+\gamma_{2} V_{2}-\mu W
\end{aligned}\right.
$$

Cada equação representa uma fração de classe da população, e denotando as epidemias como sendo causadas pelas variantes 1 ou 2, têm-se que $X(t)$ representa os suscetíveis a ambas as doenças; $Y(t)$ representa os infectados pela variante $i$ e ainda suscetíveis é variante $j ; Z(t)$ representa os recuperados

*bolsista de Iniciacão Científica PIBIC/CNPq 
pela variante $i ; V(t)$ representa os infectados pela variante $i$; mas que já foram infectados pela $j$; e $W(t)$, que denota os recuperados de ambas as doenças. Presume-se inicialmente uma população de $N=$ 102 indivíduos que varia no decorrer de 30 semanas. Para a obtenção dos dados utilizou-se o método numérico de Runge-Kutta implementado por um algoritmo computacional baseado na linguagem $\mathrm{C} / \mathrm{C}++$. Os gráficos foram obtidos fazendo uso da plataforma Origim. O sistema de equações apresenta quatro pontos de equilíbrio: o trivial não-endêmico, $P_{1}=(1,0,0,0,0,0,0) ; P_{2}=\left(\frac{1}{R_{1}}, \frac{\mu}{\gamma_{1}-\mu}\left(1-\frac{1}{R_{1}}\right), \frac{\gamma_{1}}{\gamma_{1}+\mu}(1-\right.$ $\left.\left.\frac{1}{R_{1}}\right), 0,0,0,0\right)$, relativo ao domínio endêmico da variante $1 ; P_{3}=\left(\frac{1}{R_{2}}, 0,0, \frac{\mu}{\gamma_{2}-\mu}\left(1-\frac{1}{R_{2}}\right), \frac{\gamma_{2}}{\gamma_{2}+\mu}(1-\right.$ $\left.\frac{1}{R_{2}}\right), 0,0$ ), seu simétrico relativo a variante 2 ; e $P_{4}$. Os detalhes (como condições de existência) e o último ponto foram omitidos e podem ser encontrados em (Dietz, 1975). Foram utilizados os valores $\beta_{1}=0,8 ; \beta_{2}=0,9 ; \sigma_{1}=0,9 ; \sigma_{2}=0,4 ; \mu=0,00004 ; \gamma_{1}=0,33 ; \gamma_{2}=0,33$ (Castillo-Chavez,1989), para a obtenção dos seguintes resultados:

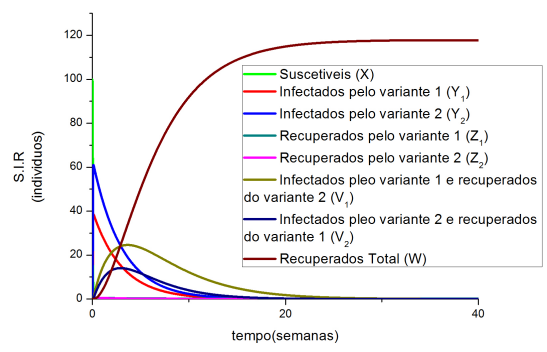

Figura 1: Variacão SIR para os dois subtipos ao longo do tempo.
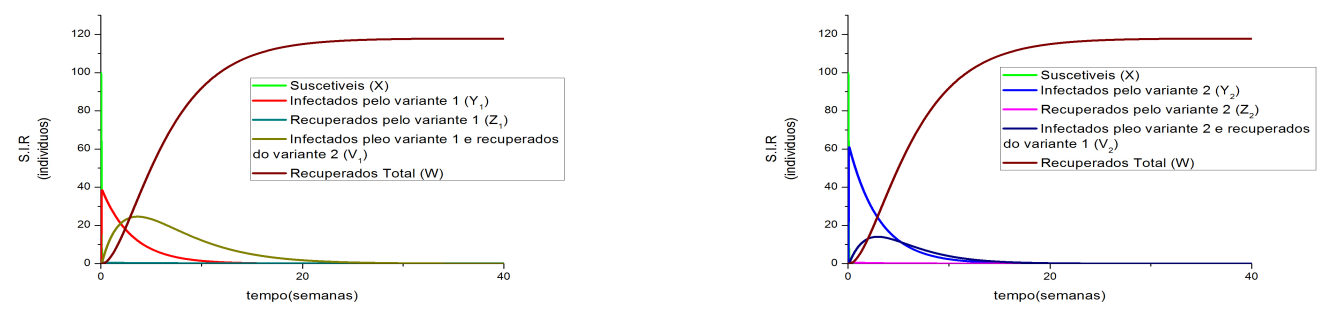

Figura 2: Variação do subtipo 1 e 2 ao longo do tempo

Nas Figuras 1, 2 e 3 observa-se que a população de indivíduos suscetíveis $X(t)$ tem um comportamento de decaimento exponencial tendendo a zero ao longo do tempo, a população de indivíduos infectados, por somente um subtipo viral $Y_{i}(t)$, apresentam comportamento parabólico atingindo um número máximo de $c_{1}=38,50$ e $c_{2}=62,80$ para a variante viral 1 e 2 , respectivamente, os indivíduos recuperados total apresentam um crescimento exponencial ao longo do tempo. O comportamento das classes de indivíduos que já foram infectados por um variante viral $V_{i}(t)$ apresentam um comportamento similar ao da população de indivíduos que foram infectados pela primeira vez. Observa-se porém, que devido a imunidade cruzada $\mu$ adiquirida por estes indivíduos o número máximo de indivíduos infectados $s_{1}=24.45$ e $s_{2}=14,07$ para o subtipo viral $l$ e 2, respectivamente, é menor em comparação ao do primeiro contato. As classes de indivíduos recuperados por somente um variante $Z_{i}(t)$ apresentam crescimento mínimo devido as altas taxas de contágio $\beta$. O modelo SIR apresenta-se como uma boa alternativa para o estudo epidemiológico por representar bem diversos aspectos da epidemia apresentando resultados biologicamente aceitáveis.

Palavras-chave: SIR, imunidade cruzada, epidemia.

\section{Referências}

[1] C, Castillo-Chavez., H, W. Hethcote., V, Andreasen., S, A. Levin., W, M. Liu. (1989),Epidemiological models with age structure, proportionate mixing, and cross-immunity, J. Math. Bioi. (1989) 27: 233-258, USA.

[2] Dietz, K.: Transmission and control of arbovirus diseases. In: Cooke, K. L. (ed.) Epidemiology, pp. 104-121. Philadelphia: Society for Industrial and Applied Mathematics (1975) 